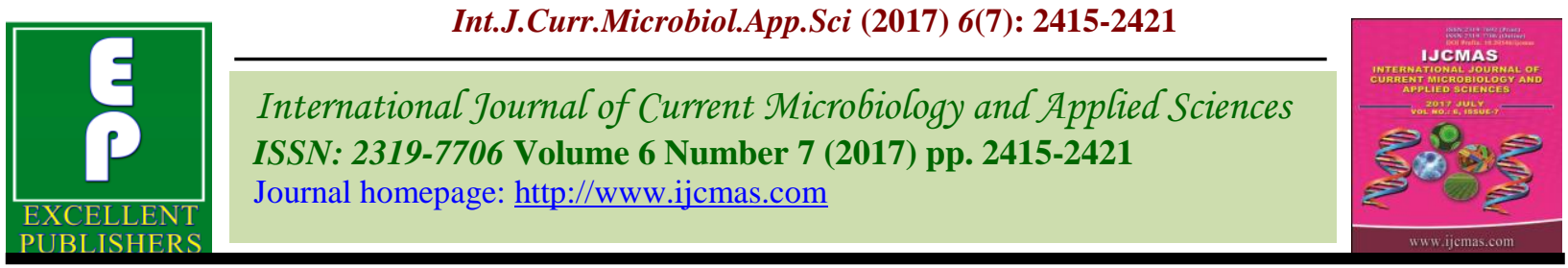

Original Research Article

https://doi.org/10.20546/ijcmas.2017.607.343

\title{
Toxicity of Some Pesticides to two Important Parasitoids of Lepidopteran Tissue Borers
}

\author{
Suvadip Saha*, P. Sudheer Kumar, Sagarika Bhowmik and Bipradeb Talukder \\ Department of Agricultural Entomology, BCKV, Mohanpur-741252, Nadia, W.B., India \\ *Corresponding author
}

\section{A B S T R A C T}

\begin{tabular}{|l|}
\hline Ke y w or d s \\
Hymenoptera, \\
Trichogramma \\
chilonis, \\
Bracon brevicornis, \\
Corcyra \\
cephalonica, \\
Mortality. \\
\hline Article Info \\
\hline $\begin{array}{l}\text { Accepted: } \\
\text { 26 June } 2017 \\
\text { Available Online: } \\
\text { 10 July } 2017\end{array}$ \\
\hline
\end{tabular}

The present study was conducted in the Bio-control laboratory, BCKV located at Mohanpur, Nadia, West Bengal, India to study the toxic effect of some modern insecticides namely cypermethrin 25\% EC @ 0.01\% a.i., wettable Sulphur 80 WP @ $0.24 \%$ a.i., profenofos 50\% EC @ $0.05 \%$ a.i., in rynaxypyr 20\% SC @ 0.006\% a.i., spiromesifen 240 SC @ 0.024\% a.i. and imidacloprid 17.8\% SL @ 0.005\% a.i., neemazal 1\% EC @ 0.002\% a.i. to the pupae of Trichogramma chilonis Ishii (Trichogrammatidae: Hymenoptera) and adults of Bracon brevicornis Wesmael (Braconidae; Hymenoptera).The results showed that Cypermethrin was found to be the most toxic insecticide $(65.52 \%$ mortality) to the pupae of $T$. chilonis followed by wettable sulphur (42.7\% mortality) and profenofos (37.08\%mortality). Toxicity of rynaxypyr, imidacloprid and spiromesifen showed low level of toxicity $(27.59 \%, 25.84 \%$ and $26.97 \%$ mortality respectively). Neemazal $1 \%$ EC was the safest ( $7.87 \%$ mortality). In case of Bracon brevicornis adults, both cypermethrin $(0.01 \%$ a.i. $)$ and wettable sulphur $(0.24 \%$ a.i. $)$ were highly toxic (70.35\% and $62.84 \%$ mortality respectively). Profenofos showed moderate level of toxicity whereas toxicity recorded in imidacloprid, spiromesifen and rynaxypyr was low $(32.43 \%$, $32.43 \%$ and $35.81 \%$ mortality respectively). Neemazal $(0.002 \%$ a.i) was found to be the safest (20.08\% mortality).

\section{Introduction}

Pesticides are integral part of present day agriculture. Pesticides are a major factor affecting biological diversity, along with habitat loss and climate change. Wide spectrum insecticides affect a biological process common to many species of insects, so these pesticides are often toxic to nontarget species as well. This is the case with both synthetic and organic insecticides, though organic insecticides usually break down to non-lethal products quickly - a trait that certain synthetic pesticides also have. However, even pesticides that break down quickly are often toxic to non-target species when exposure is direct. Conversely, if an insecticide is selectively effective only on certain species or families of insects, it is more likely to be safe for beneficial insects and pollinators. Thorough investigation of the effect of insecticides on non-target organisms will help to avoid any potential loss to the environment following their field use. By understanding the difference in toxicity levels of pesticides, a user can minimize the potential hazard by selecting the pesticide with the lowest toxicity that will control the pest and not affect other non-target organisms. Pesticides may affect natural 
enemies effectiveness either by causing direct mortality or by influencing their reproduction, behaviour, foraging or movement (Jepson, 1989 and Croft, 1990). Insecticides and acaricides are directly damaging to arthropod natural enemies whereas, the effect of fungicide and herbicides on them may not always be direct. Destruction of natural enemies through indiscriminate use of insecticides has been recognized as one of the major reason for resurgence of many noxious pests/failure of many pest management programmes.

Hymenoptera is the dominant order among all entomophagous insects both numerically and as regard to their successful use in biological control. Among them Trichogramma tids (Trichogramma tidae; Chalcidoidea), Trichogramma are minute parasite wasps that attack the eggs of many lepidopteran insects (Hassan and Abdelgader, 2001). They are the most widely studied and used biological control agents in the world. The genus contains 130 species of which 20 species have been reported from India (Singh and Jahali, 1994).

Bracon is another important parasitoid (Braconidae; Hymenoptera) which are ectoparasitoids of lepidopteran larvae living in concealed places and can easily mass reared in the laboratory (Baker et al., 1995). In the recent past a number of new generation insecticide molecules have been developed which are generally claimed to be rather selective and relatively safer to various groups of non-target organisms. However, a particular insecticide selective to a particular species may be toxic to others. In this backdrop, the present study has been undertaken to study the toxicity of some new generation insecticide molecules to two parasitoids of lepidopteran crop pest namely, Trichogramma chilonis Ishii. and Bracon brevicornis Wesmael.

\section{Materials and Methods}

Two important Hymenoptera parasitoids, the egg parasitoid, Trichogramma chilonis Ishii (Trichogramma tidae; Hymenoptera) and the ecto-larval parasitoid, Bracon brevicornis Wesmael (Braconidae; Hymenoptera) were obtained and reared in Bio-control Laboratory, Department of Agricultural Entomology, Bidhan Chandra Krishi Viswavidyalaya, West Bengal, India at $27^{\circ} \mathrm{C}$ temperature and ambient relative humidity.

\section{Insecticides used in the experiment}

The experiment was conducted with insecticides viz. Cypermethrin, Rynaxypyr, Spiromesifen, Imidacloprid, Azadirachtin, Profenofos, Wettable Sulphur. The insecticides, their formulations, trade names and address of the manufacturers are presented in table 1 .

\section{Laboratory host of the parasitoids}

The rice meal moth, Corcyra cephalonica Stainton (Galleriidae; Lepidoptera) was used as host for laboratory rearing of both the parasitoids. Sterilised crushed maize grains were used to rear the laboratory host, $C$. cephalonica Stainton.

\section{Mass culture of Corcyra cephalonica, laboratory hosts of the parasitoids}

Crushed maize grain was sterilized in oven at $100^{\circ} \mathrm{C}$ for 30 minutes before use to eliminate others insects if any. The sterilized grains, after cooling, were sprayed with $0.2 \%$ formalin to prevent the growth of mould as well as to preserve grain humidity, which has lost during heat sterilisation. Then the grains were air dried. The grains were poured into rearing boxes@2.5 kg/box and each box was inoculated with $0.5 \mathrm{cc}$ Corcyra eggs and was closed by placing the lid. The boxes were then 
kept in racks. After about 40 days, moths started emerging, that continued for 60 days. Moths were collected daily and were transferred to specially designed oviposition cages placed over a petri plate for egg laying. The eggs were collected every day, cleaned and the scales were removed by blowing by a fan. The collected eggs were either used for further rearing of Corcyra or for rearing the egg parasitoid.

\section{Mass culture of Trichogramma chilonis Ishii}

Eggs of Corcyra, not more than 24h old, were sterilized under UV light (25 watt) for 30 minutes to kill the developing embryo. These were sprinkled uniformly over paper card $(15.5 \mathrm{~cm} \times 8 \mathrm{~cm})$, smeared with a uniform thin layer of $50 \%$ aqueous solution of pure gum Arabica with the help of a camel hair brush. Egg cards were then offered to the newly emerged parasitoids for parasitisation inside a glass tube. Super parasitism was avoided by regulating host parasitoid density. The parasitoids were provided with $50 \%$ honey solution as food. The temperature of the rearing room was maintained at $27 \pm 1^{\circ} \mathrm{c}$. The egg card was removed from the tube after 24hrs and a fresh egg card was offered again for parasitisation and the process was continued till $20-25 \%$ of the parasioids were alive. Blackening of Corcyra eggs in the card indicated parasitisation and the cards were either kept as such for the emergence of adult parasitoids or utilized or the experiment.

\section{Mass culture of Bracon brevicornis Wesmael}

Bracon brevicornis was reared on grown up larvae of $C$. cephalonica. About 20 mated females are confined in a glass jar, the mouth of which was secured tightly by muslin sheet and rubber bands. A cotton swab soaked in $50 \%$ honey water solution was placed at the bottom of the jar to provide food to the adult parasitoids. About 30 full grown larvae of Corcyra are placed between two layers of facial tissue paper and were placed over the muslin sheet covering the mouth of the jar. The tissue papers are again covered with a muslin sheet and fastened tightly with rubber bands. After $24 \mathrm{hrs}$, the tissue papers containing parasitized larvae were removed and kept in plastic containers. The body remnants of Corcyra larvae were removed after pupation of B. brevicornis and the pupae were then kept in glass jars measuring $12.5 \mathrm{~cm}$ $\mathrm{x} 10 \mathrm{~cm}$ (dia) for the emergence of adult parasitoids.

\section{Preparation of different concentrations of the insecticides}

The toxicity of selected insecticides, each at two concentrations, was evaluated on the pupal and adult stages of the parasitoids. The desired concentrations were prepared by mixing measured quantities of insecticides with fresh tap water. The treatment details are provided in table 2 .

Toxicity of different insecticides on the pupae of Trichogramma spp.

For the experiment, parasitized egg cards were kept for development of the parasitoids inside the host eggs. On the fifth day after parasitisation when all the parasitized eggs have turned black indicating that, the parasitoids inside have entered pupation, the egg cards were made into pieces, each piece containing at least 50 parasitized eggs. These small cards were dipped in insecticidal solutions, removed immediately and dried under fan. In control treatment, egg cards were dipped in water. The egg cards were then kept separately in glass vials to allow the emergence of adult parasitoids from the insecticide treated host eggs. The mouth of the vials was covered with muslin cloth tied with rubber bands. The pupal mortality was recorded after adult emergence and the pupae 
from which no adult has emerged were considered as dead. Each treatment was replicated three times and observation was taken under a binocular Stereo Microscope on 30 parasitized eggs in each replication (10 from three different locations of the card)

Toxicity of insecticides on the adults of $\boldsymbol{B}$. brevicornis Wesmael

Insecticidal solutions were prepared as mentioned earlier. Field collected castor leaves were cut into pieces measuring $12.5 \mathrm{~cm}$ $x 2.5 \mathrm{~cm}$ (dia), dipped in insecticidal solution and were dried under fan. The leaves were then placed inside glass tubes measuring $12.5 \mathrm{~cm} \times 2.5 \mathrm{~cm}$ (dia) covering the entire inner surface of the tube and ten numbers of newly emerged $B$. brevicornis adult females were released within the tube. The mouth of the glass tubes was plugged with fine cloth and tied with rubber bands. Mortality was recorded after $24 \mathrm{hrs}$ and the moribund adults were considered as dead. Each treatment was replicated thrice.

\section{Statistical methods}

From the observed \% mortality in different insecticidal treatments and untreated control, corrected \% mortality of the pupae was calculated by using Abbott's formula (1925).

$\mathrm{P}^{\prime}=\mathrm{P}-\mathrm{C} / 100-\mathrm{C} X 100$

Where,

$\mathrm{P}^{\prime}=$ Corrected $\%$ mortality

$\mathrm{P}=$ Observed $\%$ mortality

$\mathrm{C}=\%$ mortality in control

\section{Results and Discussion}

The toxicity of seven pesticides (insecticides and acaricides) to the pupae to Trichogramma Chilonis Ishii (Braconidae; Hymenoptera) and adults of Bracon brevicornis Wesmael (Braconidae; Hymenoptera) evaluated in the laboratory showed the following results
Toxcity of pesticides to Trichogramma chilonis Ishii. Pupae

Data presented in table 3 showed that among the pesticidal treatments cypermethrin $25 \%$ $\mathrm{EC}$ at the rate of $0.01 \%$ a.i. was most toxic causing $65.52 \%$ mortality of the treated pupae and this treatment was statistically more toxic than all other pesticides used. Similarly, Samanta et al., (2009) found cypermethrin to be highly toxic to Trichogramma chilonis which corroborates the fineness of the present investigation. Wettable Sulphur $80 \mathrm{WP}$ at the rate of $0.24 \%$ a.i. caused $42.7 \%$ mortality of the pupae which was statistically at par with profenofos $50 \% \mathrm{EC}$ at the rate of $0.05 \%$ a.i. (37.08\% mortality). These two treatments, however, showed significantly higher toxicity than treatment with rynaxypyr, spiromesifen, imidacloprid and neemazal. Mandal and Panja (2006) reported that profenofos $0.0625 \%$ caused total mortality of Trichogramma chilonis. During the present investigation, however, profenofos $0.05 \%$ a.i. was moderately toxic to the parasitoids. Pupal mortality recorded in rynaxypyr $20 \%$ SC at the rate of $0.006 \%$ a.i., spiromesifen $240 \mathrm{SC}$ at the rate of $0.024 \%$ a.i. and imidacloprid $17.8 \% \mathrm{SL}$ at the rate of $0.005 \%$ a.i. was $27.59 \%, 25.84 \%$ and $26.97 \%$ respectively which were statistically at per among them. Karam 2007) found rynaxypyr $20 \%$ SC to be the safest to the pupae of $T$. chilonis. Jayashree et al., (2002) found imidacloprid to be safest to Trichogramma chilonis whereas Nasreen et al., (2004) reported imidacloprid as toxic to the parasitoids. On the other hand, Basappa (2007) reported imidacloprid as moderately toxic. During the present investigation, however, imidacloprid was found to be moderately toxic to Trichogramma chilonis. Differences in the experimental conditions, methodology adopted, age of the parasitoids exposed and strains of the parasitoids may also be responsible for these observed differences by the authors. 
Table.1 List of the insecticides along with their formulation and sources

\begin{tabular}{|l|l|l|l|l|}
\hline SL. No. & Insecticides & TradeNames & Formulation & Manufacturer With Address \\
\hline 1. & Cypermethrin & Super Killer & $25 \%$ EC & DhanukaAgritech Ltd \\
\hline 2. & Rynaxypyr & Coragen & $18.9 \%$ w/w SC & M/S E.I. DuPont India Pvt. Ltd. \\
\hline 3. & Spiromesifen & Oberon & $240 \mathrm{SC}$ & Bayer crop science Limited \\
\hline 4. & Imidacloprid & Confidor & $17.8 \%$ SL & Bayer crop science Limited \\
\hline 5. & Azadirachtin & Neemazal & $1 \%$ EC & E.I.D parry (India) ltd. \\
\hline 6. & Profenofos & Carina & $50 \%$ EC & PI Industries Ltd. \\
\hline 7. & WettableSulphur & Sulfex & $80 \mathrm{WP}$ & Excel industries pvt.ltd. \\
\hline
\end{tabular}

Table.2 Name of chemical with their concentrations

\begin{tabular}{|l|l|l|}
\hline S. No & Insecticides & Doses(ml/litre) \\
\hline 1 & Cypermethrin (25\% EC) & 0.4 \\
\hline 2 & Rynaxypyr (18.9\%w/w SC) & 0.3 \\
\hline 3 & Spiromesifen (240 SC) & 1 \\
\hline 4 & Imidacloprid (17.8 SL) & 0.3 \\
\hline 5 & Azadirachtin (1\% EC)) & 2 \\
\hline 6 & Profenofos (50\% EC) & 1 \\
\hline 7 & WettableSulphur (80 WP) & $3(\mathrm{gm})$ \\
\hline
\end{tabular}

Table.3 Percent mortality of Trichogramma chilonis Ishii

\begin{tabular}{|l|l|l|}
\hline S. No & Insecticides & $\%$ Pupal mortality \\
\hline 1. & Cypermethrin 25\% EC @ 0.01\% a.i. & $60.22(54.04)$ \\
\hline 2. & Rynaxypyr 20\% SC @ 0.006\% a.i. & $27.59(31.64)$ \\
\hline 3. & Spiromesifen 240 SC @ 0.024\% a.i. & $25.84(30.47)$ \\
\hline 4. & Imidacloprid 17.8 SL @ 0.005\% a.i. & $26.97(31.24)$ \\
\hline 5. & WettableSulphur 80 WP @ 0.24\% a.i. & $42.70(40.77)$ \\
\hline 6. & Profenofos 50\% EC @ 0.05\% a.i. & $37.08(37.45)$ \\
\hline 7. & Neemazal 1\% EC @ 0.002\% a.i. & $7.87(16.21)$ \\
\hline F test & Significant \\
\hline SE $(\mathrm{m}) \pm$ & 1.62 & \\
\hline CD at 5\% & 4.90 & \\
\hline
\end{tabular}

Figures in the parentheses are angular transformed values

Table.4 Percent mortality of Bracon brevicornis Wesmael

\begin{tabular}{|l|l|l|}
\hline S. No & Insecticides & \% Adult mortality \\
\hline 1. & Cypermethrin 25\% EC @ 0.01\% a.i. & $76.35(60.98)$ \\
\hline 2. & Rynaxypyr 20\% SC @ 0.006\% a.i. & $35.81(36.60)$ \\
\hline 3. & Spiromesifen 240 SC @ 0.024\% a.i. & $32.43(34.65)$ \\
\hline 4. & Imidacloprid 17.8 SL @ 0.005\% a.i. & $32.43(34.65)$ \\
\hline 5. & WettableSulphur 80 WP @ 0.24\% a.i. & $62.84(52.46)$ \\
\hline 6. & Profenofos 50\% EC @ 0.05\% a.i. & $44.59(40.69)$ \\
\hline 7. & Neemazal 1\% EC @ 0.002\% a.i. & $20.08(20.08)$ \\
\hline F test & Significant & \\
\hline SE $(\mathrm{m}) \pm$ & 2.75 & \\
\hline CD at 5\% & 8.34 & \\
\hline
\end{tabular}

Figures in the parentheses are angular transformed values 
Neemazal1\% EC at the rate of $0.002 \%$ a.i. resulted in $7.87 \%$ mortality only and was proved to be the safest to the parasitoids.

\section{Toxicity of pesticides to Bracon brevicornis Wesmael adults}

The corrected mortality of Bracon brevicornis wesmael adults after $24 \mathrm{hrs}$ exposure to the pesticides are presented in table 4. Here also cypermethrin $25 \% \mathrm{EC}$ at the rate of $0.01 \%$ a.i. was the most toxic insecticides $(70.35 \%$ mortality), followed by wettable sulphur 80 WP at the rate of $0.24 \%$ a.i. $(62.84 \%$ mortality). Reports relating to the toxicity of the pesticides to Bracon brevicornis are verylow. However, Guddewar (1992) found cypermethrin to be toxic to Bracon brevicornis whereas Chaturvedi (2005) reported cypermethrin as slightly harmful to it. Profenofos $50 \% \mathrm{EC}$ at the rate of $0.05 \%$ a.i. ranks third in respect of toxicity to the parasitoids. This treatment, however, fell to show insignificant difference from the rynaxypyr $20 \% \mathrm{SC}$ at the rate of $0.006 \%$ a.i. (35.81\% mortality). Mandal and Panja (2006) observed total mortality of Bracon brevicornis adults even at $0.037 \%$ a.i. of profenofos. During the present investigation, however, profenofos at the rate of $0.05 \%$ a.i. was relatively safe to the natural enemies. Both spiromesifen $240 \mathrm{SC}$ at the rate of $0.024 \%$ a.i. and imidacloprid $17.8 \% \mathrm{SL}$ at the rate of $0.005 \%$ a.i. produce $32.43 \%$ mortality of adults and these two treatments were statistically similar to rynaxypyr $20 \%$ SC. neemazal $1 \% \mathrm{EC}$ at the rate of $0.002 \%$ a.i. was the safest causing $20.08 \%$ mortality only to the treated adults. It is evident from the results that among treated pesticides, cypermethrin $25 \% \mathrm{EC}$ at the rate of $0.01 \%$ a.i. was highly toxic to both the natural enemies. Wettable sulphur $80 \mathrm{WP}$ at the rate of $0.24 \%$ though showed high level of toxicity to the adults' of $B$. brevicornis show moderate level of toxicity in the pupae of T.chilonis.
Wettable sulphur, an acaricide, results in moderate to high level of mortality to both the natural enemies, however, the result could not be compared with any earlier experimental data, due to lack of information.Profenofos $50 \%$ EC at the rate of $0.05 \%$ a.i., rynaxypyr $20 \% \mathrm{SC}$ at the rate of $0.006 \%$ a.i., spiromesifen $240 \mathrm{SC}$ at the rate of $0.024 \%$ a.i. and imidacloprid $17.8 \% \mathrm{SL}$ at the rate of $0.005 \%$ a.i showed moderate level of toxicity to both the parasitoids. Neemazal1\% EC at the rate of $0.002 \%$ a.i. showed exceptional safety to the natural enemies. It is also evident from the result that toxicity of the pesticides to $B$. brevicornis adults was slightly higher than the pupae of the $T$. chilonis. Though pharate adults are generally believed to be highly sensitive to the pesticides the host egg shell may act as a protective barrier thereby resulting in low mortality of the pupae. Moreover, the treatment was given just after pupation of the parasitoids inside host eggs and the young pupae may not be as susceptible as the older ones or the pharate adults.

The results from this experiment helps to conclude that neemazal $(0.002 \%$ a.i) can safely be used in the fields where both the parasitoids are active whereas cypermethrin should be applied with much caution. Rynaxypyr, spiromesifen, imidacloprid and also profenofos can be utilized without much harm to the natural enemies. Wettable sulphur should be applied with due care particularly in situations where Bracon brevicornis is active.

\section{References}

Abbott W.S. 1925. A method of computing the effectiveness of an insecticide. Journal of Economic Entomology. 18: $265-267$.

Baker, J.E., Weaver, D. K., Thorne, J. E. and Zettler, J. L. (1995). Resistance to protectant insecticides in two field 
strains of the stored-products insect parasitoid Braconhebetor (Hymenoptera; Braconidae).Journal of Economic Entomology,88: 512-519.

Basappa, H. (2007). Toxicity of biopesticides and synthetic insecticides to egg parasitoid, Trichogramma chilonis Ishii, and coccinellid predator, Cheilomenessexmaculata (Fabricius). $J$. Bio. Cont., 21(1): 31-36.

Chaturvedi, I. (2005). Relative toxicity of nine insecticides to Braconkirkpatricki andPolistesolivaceus. Resistant Pest Management Newsletter, 14(2): 30-33.

Croft, B.A. (1990). Arthropod biological control agents and pesticides. John Willey and Sons, New York.

Guddewar, M. B., Shukla, A. and Saini, M. L. (1992). Relative toxicity of Synthetic Pyrethroids to adults of Braconhebetor Say (Braconidae; Hymenoptera). PlantProtection Bulletin Faridabad, 44(1-2): 16-17.

Hassan, S.A. and H. Abdelgader, 2001. A sequential testing program to assess the side effects of pesticides on Trichogramma cacoeciae Marchal (Hym, Trichogramma tidae) IOBC/WPRS Bull. 24: 71-81

Jayashri, U., Katole, S. R., Sarade, S. V. and Deshmukh, A. Y. (2002). Effect of third day insecticidal application of the emergence of Trichogramma chilonis Ishii from parasitized host eggs. $P K V$
Res.J, 26:44-46.

Jepson, P. C. (1989). Pesticides and nontarget Invertibrates. (Ed.) Intercept. Wimborne. Dorset, U.K.

Karam, N. (2007).Non-target toxicity of some pesticides against natural enemies of insect pests. A M.Sc. thesis submitted to Bidhan Chandra Krishi Viswavidyalaya. West Bengal, Nadia. P.

Mandal, S. K., Debnath, M. and Panja, S. (2006). Effect of some herbicides on Egg Parasitism and Development of Trichogramma chilonis Ishii (Trichogramma tidae: Hymenoptera). Journal of crop and weed, 2(1):26-28.

Nasreen, A., Cheema, G. M., Ashfaq, M. and Saleem, M.A. (2004). Survival of Trichogramma chilonisIshii (Hymenoptera: Trichogrammitidae) after exposureto different insecticides: laboratory studies. Pakistan Journal of Zoology, 36(1): 79-82.

Samanta, A., Patra, S., Chakraborti, K., Ghosh, A., Hembram, T. and Somchowdhury, A. K. (2009). Relative toxicity of some insecticides against two indigenous parasites associated with Lepidopteran pests. Environment and Ecology, 27(4): 1545-1549.

Singh, S.P. and Jahali, S.K. (1994).Key to Indian Trichogramma tids. In: Trichogramma tids. PDBC, Bangalore, India (ICAR).P.6-7.

\section{How to cite this article:}

Suvadip Saha, P. Sudheer Kumar, Sagarika Bhowmik and Bipradeb Talukder. 2017. Toxicity of Some Pesticides to two Important Parasitoids of Lepidopteran Tissue Borers. Int.J.Curr.Microbiol.App.Sci. 6(7): 2415-2421. doi: https://doi.org/10.20546/ijcmas.2017.607.343 